\title{
5 Research Square

\section{Trends to Adaptation of the Sahara Frog (Pelophylax Saharicus) Larvae Across An Environmental Gradient}

Soufyane Bensouilah ( $\nabla$ soufyaneben@hotmail.com )

Universite Amar Telidji Laghouat Faculte des Sciences

\section{Rabah Zebsa}

University of 8 May 1945 Guelma Faculty of Nature and Life and Earth Sciences and the Universes:

Universite 8 Mai 1945 Guelma Faculte des Sciences de la Nature et de la Vie et Sciences de la Terre et de l'Univers

\section{Zinette Bensakhri}

University of 8 May 1945 Guelma

\section{Abdeldjalil Youcefi}

Centre Universitaire de Tamanrasset

Hichem Amari

Universite Chadli Bendjedid

\section{Amel Lazli}

Universite Chadli Bendjedid

\section{Moussa Houhamdi}

University of 8 May 1945 Guelma Faculty of Nature and Life and Earth Sciences and the Universes:

Universite 8 Mai 1945 Guelma Faculte des Sciences de la Nature et de la Vie et Sciences de la Terre et de I'Univers

\section{Rassim Khelifa}

The University of British Columbia

\section{Research Article}

Keywords: Life history, phenology, growth, elevation, desert, amphibian

Posted Date: October 25th, 2021

DOl: https://doi.org/10.21203/rs.3.rs-986730/v1

License: (c) (1) This work is licensed under a Creative Commons Attribution 4.0 International License.

Read Full License 


\section{Abstract}

Species adjust their behavior and life-history to adapt to local environmental conditions. Species with large ecological prevalence often show signatures of local adaptations to different environment, particularly in extreme ones. Here, we investigate local adaptation in different populations of the North African Sahara frog (Pelophylax saharicus) living in various environmental conditions that varies mostly in temperature, precipitation, and elevation by mean of common garden experiment aiming to estimate the growth rate under two predation treatments (absence or presence of non-lethal cues of dragonfly larvae). First, we found an elevational cline in the reproductive phenology where, from low to high elevation, the reproductive season shifts to later dates, whereas that in arid environment was later than all other populations. We suggest that geographic differences in temperature and rainfall (in arid areas) explain this phenological pattern. Second, hatching success was overall high but showed a slight decline across elevation. Third, growth rate was generally faster in low and intermediate elevation populations, but slower in high elevation and arid environment populations. Populations in low and intermediate elevation responded to predation by reducing growth rate and the size at metamorphosis, but no predatory responses were recorded in high elevation and arid environment populations. Our study shows some life history signatures of local adaptation of $P$. saharicus in Northeast Algeria, which does not go in line with recent genetic analysis showing low population differentiation in the region.

\section{Introduction}

Species adapt to local environmental conditions by adjusting their behavior and life-history traits (Schmidt-Nielsen 1997). As a result, species show intraspecific adaptive variation across environmental gradients such as latitude and elevation (Conover \& Schultz 1995; Nylin \& Gotthard 1998; Blanckenhorn \& Demont 2004; Laugen et al. 2005). In addition, one would expect that populations exposed to highly variable environments tend to express high levels of plasticity; a hypothesis that has been tested for decades (Klopfer \& MacArthur 1960; Cook \& Johnson 1968; Moran 1992; Van Buskirk 2002). In a typical Mediterranean climate where environmental conditions fluctuate spatially and temporally, species and populations should exhibit high levels of plasticity and local adaptation (Valladares et al. 2002). Here, we report a study testing the occurrence of adaptive mechanisms in four different environments based on comparative analysis of life-history of an euryece species of frog.

In amphibians, several studies have shown patterns in life-history traits across latitude (Highton 1962; Berven \& Gill 1983; Hemelaar 1988; Ashton 2002, 2004) and elevation (Pettus \& Angleton 1967; Licht 1975; Howard \& Wallace 1985; Ryser 1996; Funk et al. 2005) in both larvae and adults. The understanding of the underlying mechanisms behind those variations in life-history traits is crucial for comprehending life-history evolution and the process of adaptation (Morrison \& Hero 2003). By mean of common garden experiments on populations occurring in different environments, condition-dependent adaptive processes are often easily detected (Skelly 2004). 
Predation plays an important role in structuring populations by affecting the behavior, physiology and life history (Werner 1986; Benard 2004). Experimental studies have demonstrated that predation decreases foraging, growth rate, and body size (Relyea 2001, 2002; Van Buskirk 2002). Although these responses provide some resistance to predation (Relyea 2001; Van Buskirk 2002), they induce fitness costs to individuals that carry over to the adult stage (Van Buskirk 2000). Predation as an evolutionary force varies along geographic gradients where lower predator densities are usually found in extreme environments (e.g. higher latitudes). Investing in predation defense is costly, and theory predicts that species might prioritize other vital processes than defenses against predators (Palmer 1979; Bertness et al. 1981; Bolser \& Hay 1996; Laurila et al. 2008). To test this theory, it is insightful to assess the response to predation on different kinds of extreme environments such as high elevation and arid habitat.

Many aspects of intraspecific variation of life-history of the North African endemic Sahara frog (Pelophylax saharicus) are still poorly understood, namely the extent of adaptive plasticity across the species range. The species inhabits various habitats including oases, ponds, rivers, artificial ditches (Schleich et al. 1996). It is very abundant and widespread in Algeria and North Africa, but populations are often quite isolated, especially in arid environments (Amor et al. 2010b). Most studies on P. saharicus were carried out on morphometrics (Amor et al. 2009; Amor et al. 2010a), genetic structure (Amor et al. 2010b; Nicolas et al. 2015), diet (Hassine \& Nouira 2009), environmental sensitivity (Bellakhal et al. 2014), and life history (Meddeb et al. 2007; Oromi et al. 2011). However, experimental studies investigating the combined effect of environment and predation on $P$. saharicus are still lacking.

In this study, we investigate the phenology of reproduction, hatching success, growth rate, and response to predation of different populations of $P$. saharicus occurring in distinct environments (elevational and aridity gradient). The growth rate and predation response were estimated in a common garden experiment (for each individual separately) with standardized conditions, ad libitum food, and chemical cues from Anax dragonfly larvae used as the predation treatment. We hypothesize that life-history of the species depends on local environmental conditions where populations living in extreme environments such as high elevation and arid habitats show different reproductive phenologies and reaction norms than those living in more hospitable environments. We also hypothesize that populations in extreme environments do not slow down their pace of growth under predation due to time constraints.

\section{Methods}

\section{Study area}

The study was conducted in Northeast Algeria in an area ranging from the coast to the semi-desertic environment, across a distance of $330 \mathrm{~km}$ (Figure 1). The climate in the region is typically Mediterranean where the dry season becomes longer and temperature increases towards the south. For example, in a coastal city such as Annaba, the yearly precipitation is $632 \mathrm{~mm}$ and annual average temperature is $17.4^{\circ} \mathrm{C}$, whereas in a semi-arid city such as Biskra, the yearly precipitation is $142.9 \mathrm{~mm}$ and annual average temperature is $21.7^{\circ} \mathrm{C}$. We selected 11 sites that might be grouped into four environmental 
sectors: low elevation sites (Tonga, Estah, Lac Noir) mainly localized in the National park of El Kala (elevation range: 2-37 m), intermediate elevation sites (Beddoud, Salah Salah 1 and Salah 2) mainly localized in Guelma province (303-517 m), high elevation sites (Bendjerrah, Masmassa 1, and Masmassa

2) mainly localized in Maouna mountains in Guelma province (702-1030 m), and arid environment (Biskra 1 and Biskra 2) located in Biskra province (81-108 m) (Table 1, Figure 2).

Table 1

Study sites with geographic coordinates and elevation. Sites were grouped into sectors based environmental conditions (elevation and aridity). Sites and sectors are shown in Figure 1.

\begin{tabular}{|c|c|c|c|c|c|c|c|}
\hline Site & $\mathbf{N}$ & $\begin{array}{l}\text { Latitude } \\
\left({ }^{\circ}\right)\end{array}$ & $\begin{array}{l}\text { Longitude } \\
\left({ }^{\circ}\right)\end{array}$ & $\begin{array}{l}\text { Elevation } \\
(\mathrm{m})\end{array}$ & Sector & Habitat & Environment \\
\hline Tonga & 1 & 36.8574 & 8.5164 & 2 & $A$ & Lake & Low elevation \\
\hline Stah & 2 & 36.8436 & 7.9819 & 5 & $A$ & Pond & Low elevation \\
\hline Lac noir & 3 & 36.8531 & 8.2053 & 37 & A & Lake & Low elevation \\
\hline Bedoud & 4 & 36.5328 & 7.3800 & 303 & B & Pond & $\begin{array}{l}\text { Intermediate } \\
\text { elevation }\end{array}$ \\
\hline $\begin{array}{l}\text { Salah Salah } \\
1\end{array}$ & 5 & 36.4781 & 7.3203 & 488 & B & Pond & $\begin{array}{l}\text { Intermediate } \\
\text { elevation }\end{array}$ \\
\hline $\begin{array}{l}\text { Salah Salah } \\
2\end{array}$ & 6 & 36.4762 & 7.3174 & 517 & B & Pond & $\begin{array}{l}\text { Intermediate } \\
\text { elevation }\end{array}$ \\
\hline Benjarah & 7 & 36.4322 & 7.3782 & 702 & C & Pond & High elevation \\
\hline Masmassa1 & 8 & 36.3668 & 7.4133 & 1011 & C & Pond & High elevation \\
\hline Masmassa2 & 9 & 36.3629 & 7.4116 & 1030 & C & Pond & High elevation \\
\hline Biskra 2 & 10 & 34.8276 & 5.9139 & 81 & D & Dam & Arid environment \\
\hline Biskra 1 & 11 & 34.8484 & 5.9185 & 108 & $D$ & Pond & Arid environment \\
\hline
\end{tabular}

\section{Field sampling}

The phenology of the reproductive season was determined by carrying out weekly visits to each site from January 2015 to July 2015. We recorded the number of clutches across a standardized transect of $10 \mathrm{~m}$ along the bank of the water body. Clutches of Pelophylax saharicus are easily detectable by eye and they are mostly deposited near the banks. To estimate hatching success and growth rate, ten clutches per site were collected, put in a plastic container with water, and brought to the laboratory within 24 hours. The hatching success of each clutch was estimated based on a sample of eggs.

\section{Experimental work}

To assess growth rate across environments and predation, we first selected two sites from each sector (total number of sites $=8$ ) and randomly chose two clutches from each site. We had eight treatments in total corresponding to four environmental sectors and two predation treatments (presence and absence 
of nonlethal dragonfly larvae), under laboratory conditions $\left(21^{\circ} \mathrm{C}\right.$ and natural light conditions). A total of 12 rectangular mesocosms spatially randomized in which 40 plastic cups were set on a Styrofoam and floated on the water. All treatments were included in every single mesocosm, that is, 5 randomly placed replicates of each of the eight treatments. As soon as eggs hatched, tadpoles were individually isolated in cups filled with old tap water. Tadpoles were fed ad libitum with rabbit food every other day. Tadpoles were measured every week during which the cup was cleaned and the water was replaced. We assessed the body length (snout-vent length: SVL) by taking pictures and measuring the trait with ImageJ software. We measured body mass to the nearest $0.01 \mathrm{mg}$ using an electronic precision balance (Alexandra Scale Co). After metamorphosis, the individuals were removed from the cups. To induce non-lethal predation, 1 $\mathrm{ml}$ of mixed water of five separate large Anax sp larvae $(3-4 \mathrm{~cm})$ regularly fed by tadpoles of the same species was added to each cup of the predation treatment. We determined the peak body size (SVL and weight) for each treatment after plotting the growth curves.

\section{Statistical analyses}

All statistical analysis was conducted using R 3.5.1 (R Development Core Team 2019). Geographic variation in reproductive phenology was assessed by comparing the temporal distributions using Anderson-Darling k-Sample tests with the kSamples package (Scholz \& Zhu 2016). This analysis was carried out across all sites and within each climatic sector. We tested for potential differences across climatic sectors in hatching success and initial tadpole body size using one-way ANOVA. Then, we used posthoc Tukey tests for pairwise comparisons among sectors. Linear mixed-effects regressions were carried out to assess the elevational pattern (excluding the arid environment) of hatching success with individual, site, mesocosm, and female as random effects. The growth rate of snout-vent length (SVL) and weight were assessed by temporal segments as the typical growth of frogs goes through a slow growth phase, a fast-growth phase, and a declining phase during metamorphic climax (Tong et al. 2018). In our study species, the three phases appear to span from 1-14 days (phase 1), 15-58 days (phase 2), 59 to metamorphosis (phase 3). A mixed-effect linear regression was carried out for each phase testing for difference in reaction norms across environmental sectors and predation using the phenotypic trait (SVL and weight) as a response variable, time, sector, and predation as explanatory variables with all two-way and three-way interactions.

\section{Results}

\section{Phenology of reproduction}

The temporal pattern of reproduction was determined based on the number of clutches recorded across a standardized transect. There was a geographic variation in the start of the reproductive season of the Sahara frog $(A D=304.1, n=10, P<0.0001)$. Low elevation populations at the coast started the earliest. For instance, in Lake Noir and Estah frogs started laying eggs in mid-March. High elevation populations started about a month later, whereas populations in arid environment (low latitude) started the latest, about 50 days later. Within each sector (coastal, intermediate elevation, high elevation, and arid 
environment), there was a significant difference among sites at low ( $A D=14.26, n=4, P<0.0001)$ and intermediate elevation $(A D=40.0, n=3, P<0.0001)$, but there was no significant difference among sites at high elevation $(A D=0.04, n=2, P=0.99)$ and arid environment $(A D=0.57, n=2, P=0.67)$.

\section{Hatching success}

The average hatching success across all sites was $0.96 \pm 0.04(\mathrm{~N}=311)$. There was a significant difference among sectors in hatching success (ANOVA: $F_{3,307}=7.82, \mathrm{P}<0.0001$ ). All pairwise comparison between the four sectors showed no significant difference (Tukey test: $P>0.05$ ), except for the intermediate elevation and arid environment $(\Delta=-0.12[-0.21--0.03], P=0.001)$ and low elevation and intermediate elevation $(\Delta=0.14[0.06-0.22], \mathrm{P}<0.0001)$. By excluding the arid environment populations, there was a weak negative elevational decline in the hatching success (linear model: $R^{2}=0.04$, $\mathrm{P}=0.0008)$.

\section{Initial body size of larvae}

The initial size of tadpoles was estimated based on body length and weight. Initial body length was significantly different across sectors (ANOVA: $F_{3,307}=12.9, P<0.0001$ ). All pairwise combinations showed a significant difference (Tukey test: $P<0.0001$ ), except for the intermediate and high elevation (Tukey test: $P=0.96)$. The initial body was longest in intermediate and high elevation $(0.63 \pm 0.03 \mathrm{~cm}$ $[\mathrm{n}=60], 0.63 \pm 0.02 \mathrm{~cm}[\mathrm{n}=80]$, respectively), relatively smaller in arid environment $(0.59 \pm 0.04 \mathrm{~cm}[\mathrm{n}=80])$ and low elevation $(0.57 \pm 0.03 \mathrm{~cm}[\mathrm{n}=80])$. Initial weight was significantly different across sectors (ANOVA: $\left.F_{3,296}=3.94, P=0.008\right)$, but it shows a different pattern than that of SVL. Except for the combination intermediate and high elevation (Tukey test: $P=0.009$ ), all other pairwise combinations showed no significant difference (Tukey test: $\mathrm{P}>0.05$ ).

\section{Growth rate and predation}

Snout-vent length. There was variability among sectors in the growth rate calculated based on body length, head length, and weight (Figure 3). In the first 14 days, the linear regression showed significant time-by-sector interaction (ANOVA: $P<0.0001$ ) showing that the fastest growing populations were those at high elevation and arid environment and the slowest growing populations were those at low elevation. Predation reduced the growth rate in all sectors, revealed by the significant interaction of time and predation (ANOVA: $P=0.008)$ and the non-significant three-way interaction between time, sector, and predation (ANOVA: $P=0.25$ ). Between 15 and 58 days, the growth of body length was fastest in low and intermediate elevation, revealed by the significant interaction between time and sector (ANOVA: $P<$ 0.0001) (Figure 4). Predation did not change the growth pattern across sectors, showed by the nonsignificant interaction between predation and time (ANOVA: $P=0.35)$ and three-way-interaction (ANOVA: $P=0.27$ ) (Figure 4).

Body weight. Tadpole weight showed similar growth pattern than body length (Figure 5). In the first 14 days, growth of weight was different among sectors (ANOVA: $P<0.0001$ ); it was fastest in high elevation, relatively fast in intermediate elevation and arid environment, and slowest in low elevation (Figure 6). The 
non-significant interaction between time and predation (ANOVA: $\mathrm{P}=0.46$ ) and three-way interaction (ANOVA: $P=0.49$ ) shows that predation did not affect the pattern of weight growth. Between 15 and 58 days, weight growth increased dramatically, but the increase differed across sectors (timexsector: $\mathrm{P}<0.0001$ ), but similar pattern across predation treatments (timexsectorxpredation: $\mathrm{P}=0.08$ ) (Figure 6). Weight growth of low and intermediate elevation populations was slightly faster than high elevation and arid environment.

Larvae from different sectors reached different peaks during their growth, and those peaks were reduced by predation. The highest peak of SVL and weight was recorded in low and intermediate elevation, and the lowest in high elevation and arid environment.

\section{Discussion}

The adaptation of life history of the Saharan frog across an environmental gradient that differs in annual rainfall patterns and temperature has received little research attention. Our study includes hot arid environment, wet coastal environment, and cold high elevation environment. By mean of common garden experiment and field survey, we documented some important life-history traits, including the phenology of reproduction, body size at hatching, growth rate, and growth response to predation. Our study is one of the first to present evidence of adaptation of Pelophylax saharicus to local environment in Algeria.

\section{Phenology of reproduction}

The phenology depended on local environmental conditions. From low to high elevation, phenology shifted to later dates, which is consistent with what has been found in other frog species (Klaus \& Lougheed 2013) and other taxa (Parmesan 2007). Frogs start to breed when the environmental conditions become favorable (Duellman \& Trueb 1994), especially regarding water temperature (Brenner 1969). This hypothesis is consistent with the common response of phenology to warming of different species of frogs and other taxa (Primack et al. 2009). Interestingly, the phenology at arid environment started later than northern populations. This was probably due to the seasonal variability in precipitation where frogs start to reproduce as soon as the water becomes available (Jakob et al. 2003). Unlike in other desert frogs (e.g. Rana yavapaiensis) which deposit eggs in two annual episodes in spring and fall (Sartorius \& Rosen 2000), we recorded only one breeding season in our arid habitat.

\section{Hatching success}

The overall high hatching success was comparable with estimates of other studies on the same species (Bellakhal et al. 2017). Hatching success showed a slight decline in hatching success across elevation. Different factors might be related to hatching success but mostly, ultraviolet radiation was shown to reduce hatching success in Ranid (Ovaska et al. 1997). Typically, UV radiation increases with elevation and this might be the case in our study (Blumthaler et al. 1997) which increases the probability of egg mortality. Other causes of mortality might be pesticides sprayed in agricultural lands (Berrill et al. 1994). 
Our study sites at intermediate and high elevations were near agricultural areas, thus a potential contamination of eggs by toxic chemical compounds is likely.

\section{Initial body size of larvae}

We found that body length of tadpoles at hatching was positively correlated with elevation where high elevation populations had longer body. This is consistent with Bergman's rule which states that populations living in colder environment tend to have larger size (Blackburn et al. 1999), but not in line with other studies that found a complex relationship (Laugen et al. 2005) or the opposite trend (Ma et al. 2009). The increase of body length across elevation in the Sahara frog was not correlated with an increase in body weight, although the latter are often positively correlated (Santini et al. 2018).

\section{Growth rate and predation}

Growth trajectories showed differences across sectors. The growth pattern can be divided into three main phases. The first phase (1-14 days) was faster in extreme environments, i.e. arid environment and high elevation. This is consistent with studies in cold environments such as high latitude showing the accelerated growth rate as an adaptive mechanism to cope with shorter growth season (Ashton 2002). However, the difference in growth rate among sectors switched in the second phase (15-58 days) where low and intermediate elevation became the faster-growing populations. It is likely that fast growth might be important to reach a critical size. The third phase had a hump shape where the body size declined, which is typical during the metamorphic climax (Riis 1991). Such a quadratic geographic pattern has also been recorded in large mammals across latitude for the maximum body size (Geist 1987).

It is likely that the harsh environment in addition to the short growth season induce individuals to allocate energy into other processes than growth (energy reserve) or that larger bodied individuals might be disadvantaged due to lower food availability at the adult stage. A decline in body size at metamorphosis in extreme environments was already observed in Rana temporaria in northern Sweden (Laugen et al. 2005) and in large mammals (Geist 1987). Although smaller body size in arid environment might be adaptive for thermoregulation and heat tolerance (Kobelt \& Linsenmair 1995), studies have shown that larger individuals lose less water and have higher tolerance (Nevo 1973). This suggests that smaller size might be correlated with smaller niche width due to lower prey availability (Christian 1982) or other behavioral mechanisms such as predation avoidance.

\section{Predation}

The response of growth trajectories was sensitive to predation in early larval age where tadpoles under predation grew slower. This is probably the result of reduced activity and lower food intake (Babbitt 2001). After two weeks of growth, predation affected only the growth pattern of low elevation population but not of other populations. It is likely that the other populations are under time constraint, thus the costs of delaying metamorphosis is higher than the predation risk. Similar findings were reported for northern populations of Rana temporaria in which larvae tended to ignore predation risk (Orizaola et al. 2013). As a result of differential growth patterns across environments, size at metamorphosis declined as a 
response to predation cues in low elevation, declined slightly in intermediate elevation, but did not differ from the control in high elevation and arid environment. At low and intermediate elevation, a decline in size at metamorphosis is concordant with the response of many anurans to predators (Altwegg \& Reyer 2003). In these environmental sectors, the growth season is long and larvae are not time-constrained which reduces the costs of delayed development due to predators. The absence of predation costs on body size at metamorphosis of populations in high elevation and arid environment might be adaptive. Studies on ranids have commonly shown a reduction in growth rate due to predation (Van Buskirk 2000), but in extreme environments, it is likely that the costs of seasonality are already high enough to respond to predation and that individuals reached the limit of their life-history plasticity (Orizaola et al. 2013).

Our results show how the Sahara frog which occurs in a wide range of habitats and environments in North Africa cope with local environmental conditions and predation. The species shows life-history adaptation which is mostly characterized by reduction in body size in extreme environments such as high elevation and arid areas. Across elevation, body size showed a hump-shaped pattern where the peak body size was recorded in intermediate elevations (300-500 m). The response of the species to predation was observed only in low and intermediate elevation where individuals reached metamorphosis at smaller size but were not detected in high elevation and arid environment. This is the first experimental investigation of adaptation to various types of environments. Further studies should explore plasticity of important fitness components such as fecundity and life span and the role of biotic factors such as intraspecific competition across a large environmental gradient.

\section{Declarations}

\section{Acknowledgements}

We are thankful to anonymous reviewers for their constructive comments and suggestions. We are indebted to the lab technician Leila and all students who helped in the experiment. This study is supported by the Algerian ministry of high education and scientific research

Funding This study was not funded by any sources

Conflict of interest The authors declare no conflicts of interest

Ethics approval not applicable

Consent to participate not applicable

Consent for publicationh not applicable

Availability of data and material The datasets used and/or analyzed during the current study are available from the corresponding author on reasonable request

Authors' contributions not applicable 


\section{References}

1. Altwegg R, Reyer HU (2003) Patterns of natural selection on size at metamorphosis in water frogs. Evolution 57:872-882

2. Amor N, Farjallah S, Benyacoub S, Merella P, Said K (2010a) Karyological and morphometric variation of the North African green frog Pelophylax saharicus (Anura) in north-eastern Africa. Curr Zool 56:678-686

3. Amor N, Farjallah S, Said K (2009) Morphometric variation in the Tunisian green frog, Rana saharica Anura: Ranidae. Afr Zool 44:194-203

4. Amor N, Velo-Antón G, Farjallah S, Said K (2010b) Genetic variation across Tunisian populations of the anuran species Discoglossus pictus and Pelophylax saharicus. Afr Zool 45:121-128

5. Ashton KG (2002) Do amphibians follow Bergmann's rule? Can J Zool 80:708-716

6. Ashton KG (2004) Sensitivity of intraspecific latitudinal clines of body size for tetrapods to sampling, latitude and body size. Integr Comp Biol 44:403-412

7. Babbitt K (2001) Behaviour and growth of southern leopard frog (Rana sphenocephala) tadpoles: effects of food and predation risk. Can J Zool 79:809-814

8. Bellakhal M, Neveu A, Fartouna-Bellakhal M, Missaoui H, Aleya L (2014) Effects of temperature, density and food quality on larval growth and metamorphosis in the north African green frog Pelophylax saharicus. J Therm Biol 45:81-86

9. Bellakhal M, Neveu A, Fertouna-Bellakhal M, Aleya L (2017) Artificial wetlands as tools for frog conservation: stability and variability of reproduction characteristics in Sahara frog populations in Tunisian man-made lakes. Environ Sci Pollut Res 24:26658-26669

10. Benard MF (2004) Predator-induced phenotypic plasticity in organisms with complex life histories. Annu Rev Ecol Evol Syst 35:651-673

11. Berrill M, Bertram S, McGilliray L, Kolohon M, Pauli B (1994) Effects of low concentrations of forestuse pesticides on frog embryos and tadpoles. Environmental Toxicology Chemistry: An International Journal 13:657-664

12. Bertness MD, Garrity SD, Levings SC (1981) Predation pressure and gastropod foraging: A tropicaltemperate comparison. Evolution 35:995-1007

13. Berven KA, Gill DE (1983) Interpreting geographic variation in life-history traits. Am. Zool 23.: 85-97

14. Blackburn TM, Gaston KJ, Loder N (1999) Geographic gradients in body size: a clarification of Bergmann's rule. Divers Distrib 5:165-174

15. Blanckenhorn W, Demont M (2004) Bergmann and converse Bergmann latitudinal clines in arthropods: two ends of a continuum? Integr Comp Biol 44:413-424

16. Blumthaler M, Ambach W, Ellinger R (1997) Increase in solar UV radiation with altitude. J Photochem Photobiol B: Biol 39:130-134 
17. Bolser RC, Hay ME (1996) Are tropical plants better defended? Palatability and defenses of temperate vs. tropical seaweeds. Ecology 77:2269-2286

18. Brenner FJ (1969) The role of temperature and fat deposition in hibernation and reproduction in two species of frogs. Herpetologica 25:105-113

19. Christian KA (1982) Changes in the food niche during postmetamorphic ontogeny of the frog Pseudacris triseriata. Copeia 1982: 73-80

20. Conover DO, Schultz ET (1995) Phenotypic similarity and the evolutionary significance of countergradient variation. Trends Ecol Evol 10:248-252

21. Cook SA, Johnson MP (1968) Adaptation to heterogeneous environments. I. Variation in heterophylly in Ranunculus flammula L. Evolution 22:496-516

22. Duellman WE, Trueb L (1994) Biology of amphibians. JHU press

23. Funk WC, Blouin MS, Corn PS, Maxell BA, Pilliod DS, Amish S et al (2005) Population structure of Columbia spotted frogs (Rana luteiventris) is strongly affected by the landscape. Mol Ecol 14:483496

24. Geist V (1987) Bergmann's rule is invalid. Can J Zool 65:1035-1038

25. Hassine B, Nouira S (2009) Diet of Discoglossus pictus Otth 1837 (Anura, Alytidae) and Pelophylax saharicus (Boulenger in Hartert, 1913) in the oases of Kettana (Gabes, Tunisia). B Soc Zool Fr 134:321-332

26. Hemelaar A (1988) Age, growth and other population characteristics of Bufo bufo from different latitudes and altitudes. J Herpetol 22:369-388

27. Highton R (1962) Geographic variation in the life history of the slimy salamander. Copeia 1962.: 597613

28. Howard JH, Wallace RL (1985) Life history characteristics of populations of the long-toed salamander (Ambystoma macrodactylum) from different altitudes. Am. Midl. Nat 113.: 361-373

29. Jakob C, Poizat G, Veith M, Seitz A, Crivelli AJ (2003) Breeding phenology and larval distribution of amphibians in a Mediterranean pond network with unpredictable hydrology. Hydrobiologia 499:5161

30. Klaus SP, Lougheed SC (2013) Changes in breeding phenology of eastern Ontario frogs over four decades. Ecology evolution 3:835-845

31. Klopfer PH, MacArthur RH (1960) Niche size and faunal diversity. The American Naturalist 94.: 293300

32. Kobelt F, Linsenmair K (1995) Adaptations of the reed frog Hyperolius viridiflavus (Amphibia, Anura, Hyperoliidae) to its arid environment. VII. The heat budget of Hyperolius viridiflavus nitidulus and the evolution of an optimized body shape. J Comp Physiol B 165:110-124

33. Laugen AT, Laurila A, Jönsson KI, Söderman F, Merilä J (2005) Do common frogs (Rana temporaria) follow Bergmann's rule? Evol. Ecol Res 7:717-731 
34. Laurila A, Lindgren B, Laugen AT (2008) Antipredator defenses along a latitudinal gradient in Rana temporaria. Ecology 89:1399-1413

35. Licht LE (1975) Comparative life history features of the western spotted frog, Rana pretiosa, from low-and high-elevation populations. Can J Zool 53:1254-1257

36. Ma X, Lu X, Merilä J (2009) Altitudinal decline of body size in a Tibetan frog. J. Zool 279.: 364-371

37. Meddeb C, Nouira S, Cheniti TL, Walsh PT, Downie J (2007) Age structure and growth in two Tunisian populations of green water frogs Rana saharica: a skeletochronological approach. The Herpetological Journal 17:54-57

38. Moran NA (1992) The evolutionary maintenance of alternative phenotypes. Am Nat 139:971-989

39. Morrison C, Hero JM (2003) Geographic variation in life-history characteristics of amphibians: a review. J Anim Ecol 72:270-279

40. Nevo E (1973) Adaptive variation in size of cricket frogs. Ecology 54:1271-1281

41. Nicolas V, Mataame A, Crochet PA, Geniez P, Ohler A (2015) Phylogeographic patterns in north African water frog Pelophylax saharicus (Anura: Ranidae). J Zool Syst Evol Res 53:239-248

42. Nylin S, Gotthard K (1998) Plasticity in life-history traits. Annu Rev Entomol 43:63-83

43. Orizaola G, Dahl E, Nicieza AG, Laurila A (2013) Larval life history and anti-predator strategies are affected by breeding phenology in an amphibian. Oecologia 171:873-881

44. Oromi N, Brunet P, Taibi K, Aït Hammou M, Sanuy D (2011) Life-history traits in Pelophylax saharicus from Tiaret semiarid lands (northwestern Algeria). The Herpetological Journal 21:267-269

45. Ovaska K, Davis TM, Flamarique IN (1997) Hatching success and larval survival of the frogs Hyla regilla and Rana aurora under ambient and artificially enhanced solar ultraviolet radiation. Can $\mathrm{J}$ Zool 75:1081-1088

46. Palmer AR (1979) Fish predation and the evolution of gastropod shell sculpture: experimental and geographic evidence. Evolution 33:697-713

47. Parmesan C (2007) Influences of species, latitudes and methodologies on estimates of phenological response to global warming. Glob Change Biol 13:1860-1872

48. Pettus D, Angleton GM (1967) Comparative reproductive biology of montane and piedmont chorus frogs. Evolution 21:500-507

49. Primack RB, Ibáñez I, Higuchi H, Lee SD, Miller-Rushing AJ, Wilson AM et al (2009) Spatial and interspecific variability in phenological responses to warming temperatures. Biol Conserv 142:25692577

50. R Development Core Team (2019) R: A Language and Environment for Statistical Computing. Vienna, Austria. R Foundation for Statistical Computing

51. Relyea RA (2001) Morphological and behavioral plasticity of larval anurans in response to different predators. Ecology 82:523-540

52. Relyea RA (2002) The many faces of predation: how induction, selection, and thinning combine to alter prey phenotypes. Ecology 83:1953-1964 
53. Riis N (1991) A field study of survival, growth, biomass and temperature dependence of Rana dalmatina and Rana temporaria larvae. Amphibia-Reptilia 12:229-243

54. Ryser J (1996) Comparative life histories of a low-and a high-elevation population of the common frog Rana temporaria. Amphibia-Reptilia 17:183-195

55. Santini L, BENÍTEZ-LÓPEZ A, Ficetola GF, Huijbregts MA (2018) Length-mass allometries in amphibians. Integr Zool 13:36-45

56. Sartorius SS, Rosen PC (2000) Breeding phenology of the lowland leopard frog (Rana yavapaiensis): implications for conservation and ecology. The Southwestern Naturalist 45:267-273

57. Schleich HH, Kästle W, Kabisch K (1996) Amphibians and reptiles of North Africa. Koeltz scientific books, Koenigstein Germany

58. Schmidt-Nielsen K (1997) Animal physiology: adaptation and environment. Cambridge University Press

59. Scholz F, Zhu A (2016) kSamples: K-sample Rank Tests and their Combinations. $R$ package version $1: 2-3$

60. Skelly DK (2004) Microgeographic countergradient variation in the wood frog, Rana sylvatica. Evolution 58:160-165

61. Tong Q, Du X-p, Hu Z-f, Cui L-y, Wang H-b (2018) Modelling the growth of the brown frog (Rana dybowskii). PeerJ 6:e4587

62. Valladares F, Balaguer L, Martinez-Ferri E, Perez-Corona E, Manrique E (2002) Plasticity, instability and canalization: is the phenotypic variation in seedlings of sclerophyll oaks consistent with the environmental unpredictability of Mediterranean. ecosystems? New Phytol 156:457-467

63. Van Buskirk J (2000) The costs of an inducible defense in anuran larvae. Ecology 81.: 2813-2821

64. Van Buskirk J (2002) A comparative test of the adaptive plasticity hypothesis: relationships between habitat and phenotype in anuran larvae. Am Nat 160:87-102

65. Werner EE (1986) Amphibian metamorphosis: growth rate, predation risk, and the optimal size at transformation. Am Nat 128:319-341

\section{Figures}




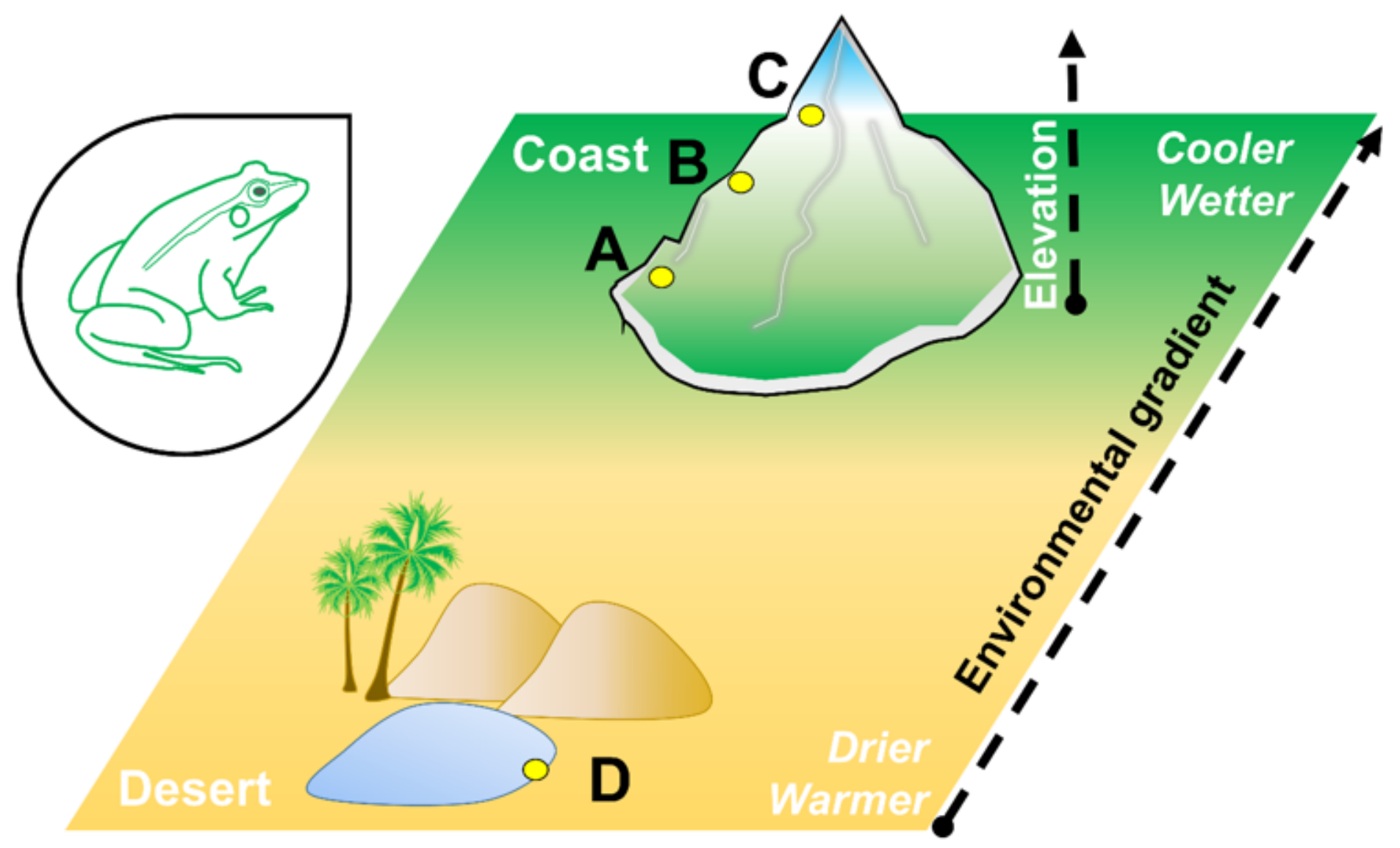

Figure 1

Environmental gradient of the studied sectors in Northeast Algeria. From south to north and from low to high elevation, temperature and precipitation change substantially.

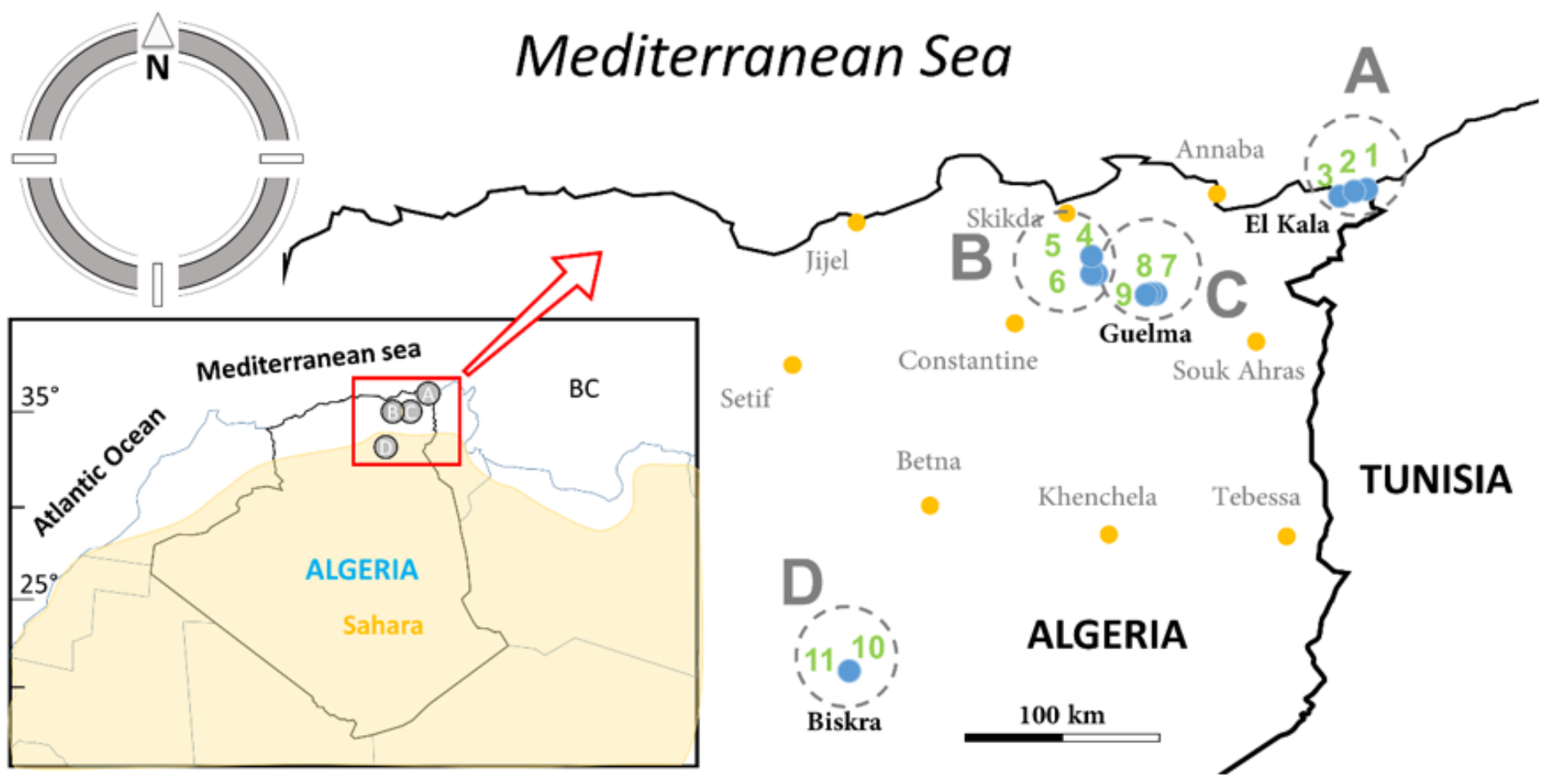


Figure 2

Map representing the distribution of the study sites in Northeast Algeria. Southern, Northern and coastal sites are referred to as A, B, C, respectively. Blue points are study sites. Orange sites are the main cities.

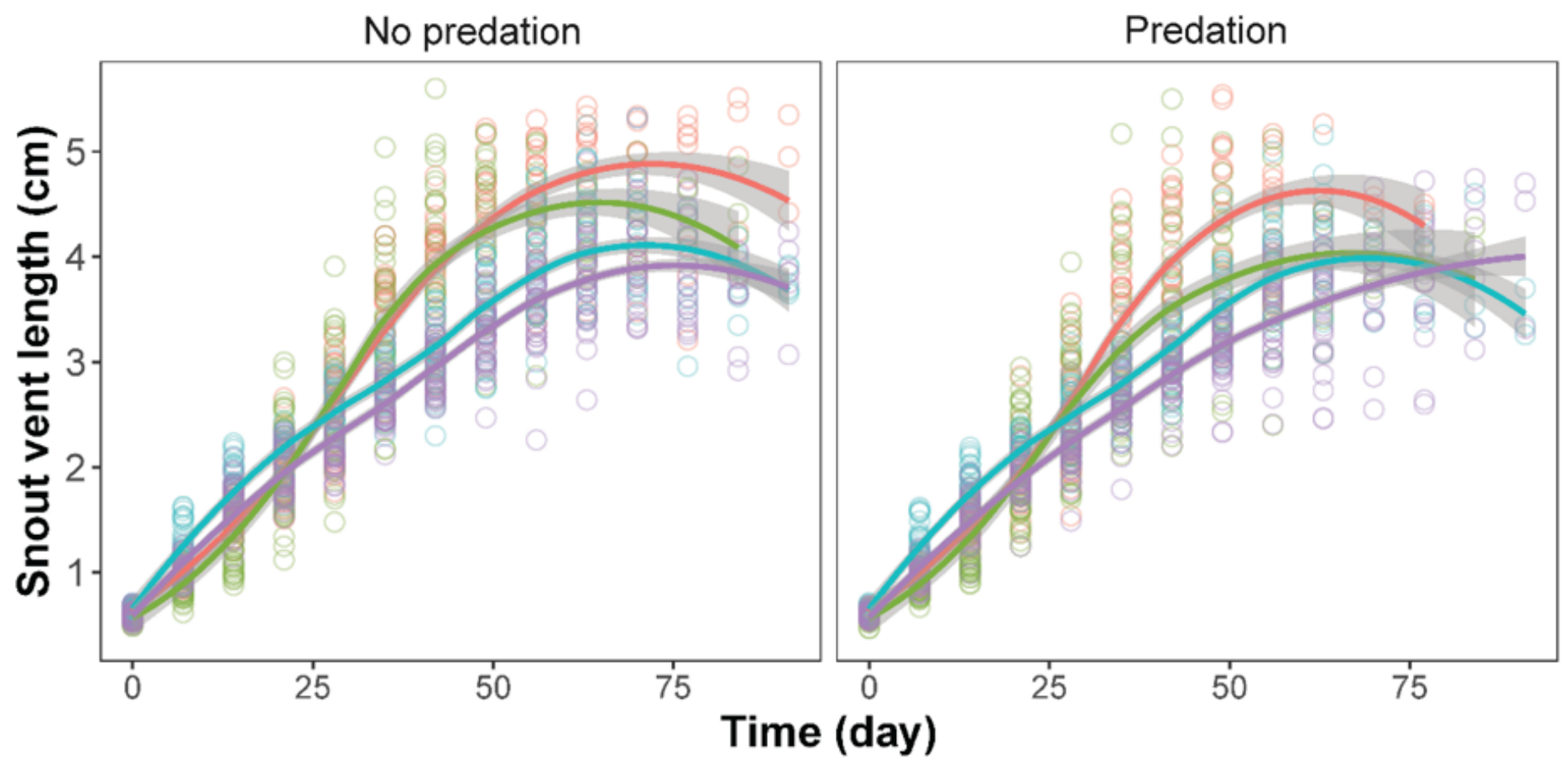

Figure 3

Growth curves of the snout-vent length of Pelophylax saharicus in four environmental sectors. Red: Low elevation, green: intermediate elevation, blue: high elevation, purple: arid environment. The curves were fitted with a loess function.

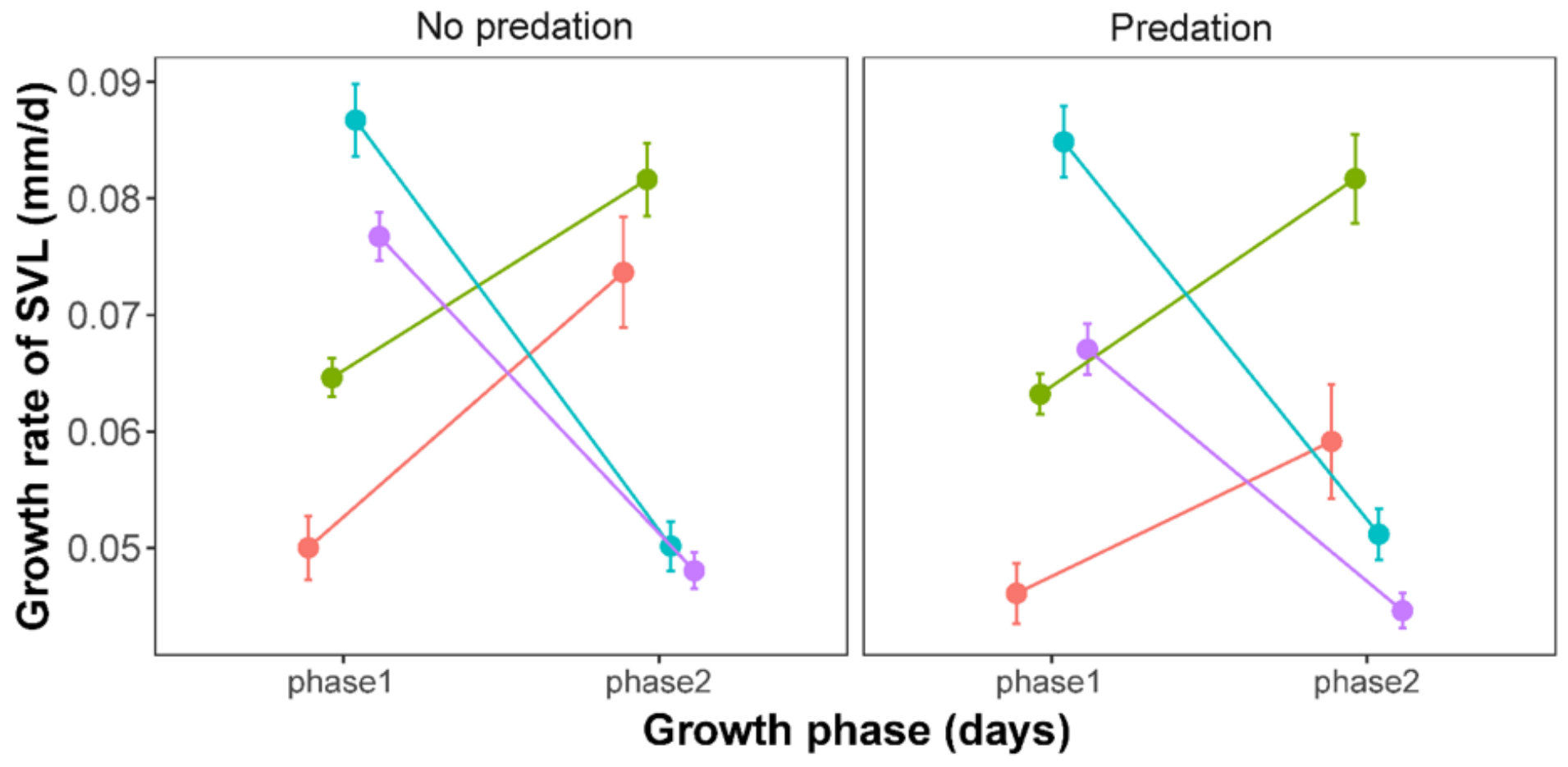


Figure 4

Slopes of growth rates of the snout-vent length of Pelophylax saharicus during two phases (phase 1: 1-14 days; phase 2: 15-58 days) in four environmental sectors. Red: Low elevation, green: intermediate elevation, blue: high elevation, purple: arid environment. The error bars are standard errors.

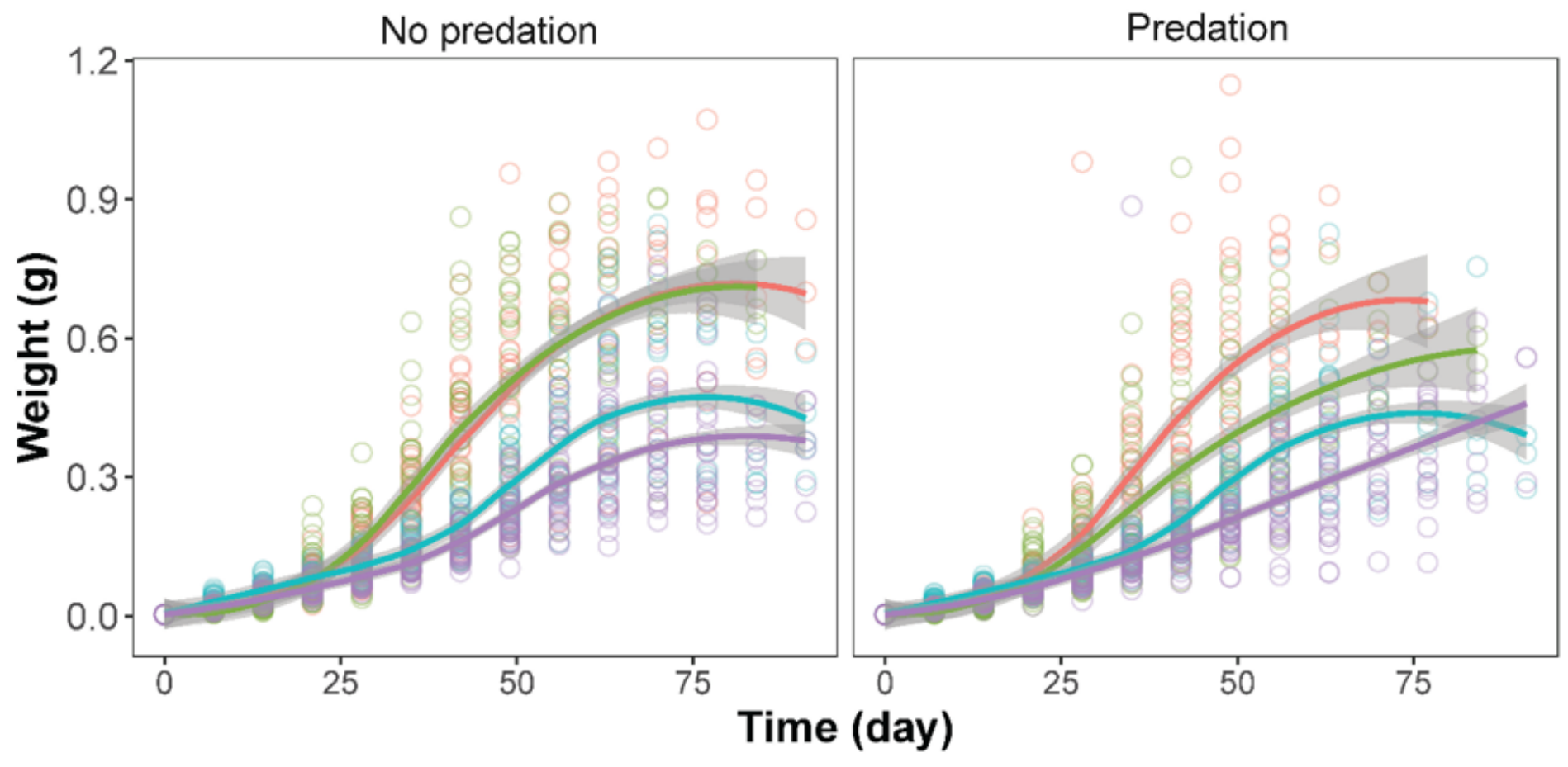

Figure 5

Growth curves of the fresh weight of Pelophylax saharicus in four environmental sectors. Red: Low elevation, green: intermediate elevation, blue: high elevation, purple: arid environment. The curves were fitted with a loess function. 


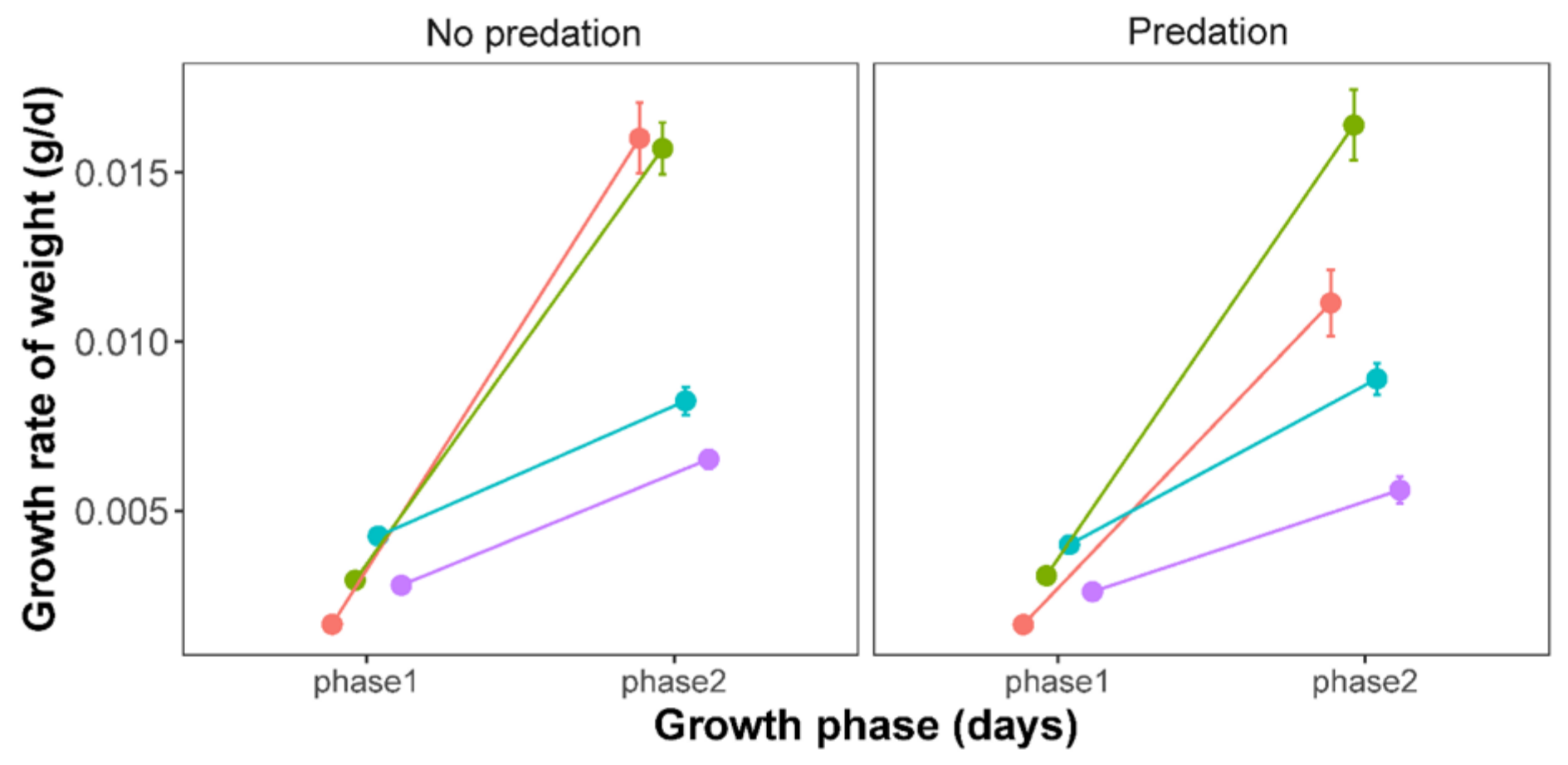

Figure 6

Slopes of growth rates of body weight of Pelophylax saharicus during two phases (phase 1: 1-14 days; phase 2: 15-58 days) in four environmental sectors. Red: Low elevation, green: intermediate elevation, blue: high elevation, purple: arid environment. The error bars are standard errors.
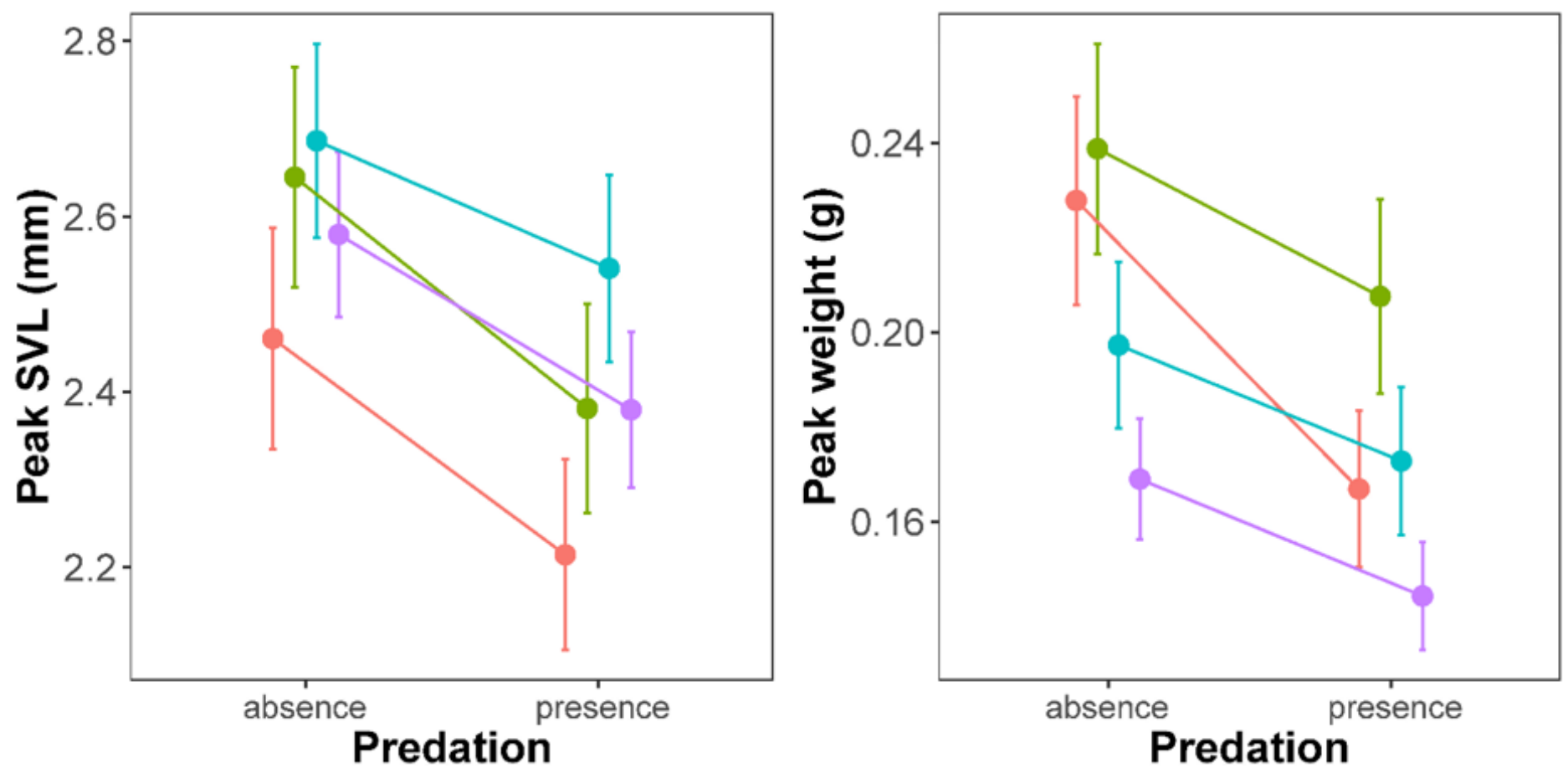

Figure 7 
Peak SVL and body weight during the growth of Pelophylax saharicus from four environmental sectors and raised under two predation treatment (presence and absence). Red: Low elevation, green:

intermediate elevation, blue: high elevation, purple: arid environment. Error bars are $95 \%$ confidence intervals.

\section{Supplementary Files}

This is a list of supplementary files associated with this preprint. Click to download.

- Supplementarymaterial.docx 